\title{
Anticancer potential of an ethanol extract of Asiasari radix against HCT-116 human colon cancer cells in vitro
}

\author{
SE-MI OH, JINHEE KIM, JUN LEE, JIN-MU YI, DAL-SEOK OH, OK-SUN BANG and NO SOO KIM
}

KM-Based Herbal Drug Research Group, Korea Institute of Oriental Medicine, Daejeon 305-811, Republic of Korea

Received August 1, 2012; Accepted October 30, 2012

DOI: $10.3892 / \mathrm{ol} .2012 .1012$

\begin{abstract}
Radix of Asiasarum heterotropoides var. mandshuricum $\mathrm{F}$. Maekawa (A. radix) has been prescribed for treating pain, allergies and inflammatory disorders in traditional oriental medicine. However, only limited information on the anticancer effects of $A$. radix is currently available. The aim of this study was to determine the anticancer effect of the ethanol extract of A. radix (EEAR) on HCT-116 human colon cancer cells and to investigate its underlying mechanisms of action. EEAR significantly induced G2/M cell cycle arrest and apoptosis in HCT-116 cells. EEAR-induced apoptosis was observed in parallel with activation of caspases and an increased ratio of Bax (pro-apoptotic)/Bcl2 (anti-apoptotic). Western blot analyses revealed that EEAR elevated the expression of $\mathrm{p} 53$ and $\mathrm{p} 21^{\mathrm{Waf} / \mathrm{Cip} 1}$ and decreased the expression of the regulator proteins of $\mathrm{G} 2 / \mathrm{M}$ phase progression, such as cdc2 and cyclin B. The upregulation of p53 by EEAR was due to the increased levels of p53 mRNA without a similar increase in proteasome-mediated p53 degradation. EEAR-induced apoptosis in HCT-116 cells was dependent on p53 expression, as determined by siRNA-mediated p53 knockdown. Taken together, these results suggest that EEAR inhibits the growth of the HCT-116 cells through induction of G2/M cell cycle arrest and apoptosis, which are mediated by p53 expression.
\end{abstract}

\section{Introduction}

Human colorectal cancer (CRC) affects $6 \%$ of the world's population and is the third most common cancer in Western countries (1). If metastasis occurs, the 5-year survival rate of CRC is $\sim 10 \%$ (2). CRC in Korea was known to be less prevalent than in Western countries; however, the 2011 cancer survey by the Korean Society of coloproctology reported that the incidences of CRC in Korean males and females were 46.9 and 25.6 per 100 thousand people, respectively, and the incidence

Correspondence to: Dr No Soo Kim, KM-Based Herbal Drug Research Group, Korea Institute of Oriental Medicine, 1672 Yuseong-daero, Yuseong-gu, Daejeon 305-811, Republic of Korea E-mail: nosookim@kiom.re.kr

Key words: anticancer, cell cycle arrest, apoptosis, HCT-116, p53 is expected to increase up to two-fold by 2030. The upsurge of CRC incidence in Korea may be related to changes in lifestyle, such as the Western culinary culture. CRC is now becoming a serious public health problem.

Uncontrolled proliferation of cancer cells is closely associated with genetic mutations in cell cycle regulators, signal-regulated kinases and tumor suppressors. Therefore, the majority of the strategies for developing chemotherapeutic anticancer agents target these regulatory proteins to inhibit tumor growth. In CRC, genetic mutations in $A p c, K R A S$, PIK3CA, p53 and Src are known to promote tumor growth (3). In addition to genetic mutations, environmental factors, such as obesity, are risk factors for CRC. The effectiveness of chemotherapy against $\mathrm{CRC}$ varies among patients due to the heterogeneous nature of $\mathrm{CRC}$; hence, a specific therapeutic regime may be required for each individual CRC case (3).

Medicinal herbs used in traditional oriental medicine are attractive sources for developing novel therapeutics or preventives, since they have been used for thousands of years in clinics. Therefore, they have been pre-validated for effectiveness and are expected to have fewer safety issues than chemically synthesized drugs. Asiasarum heterotropoides var. mandshuricum $\mathrm{F}$. Maekawa is a perennial plant that grows in East Asian countries, including Korea, China and Japan. The radix of Asiasarum heterotropoides var. mandshuricum $\mathrm{F}$. Maekawa (A. radix) is called seshin in Korean, saishin in Japanese, or Chinese wild ginger in English. In traditional Korean medicine, A. radix has been used as an antibiotic or anti-nociceptive for treating arthralgia and diverse pains (4). In Japanese herbal medicine (kampo), A. radix has been used as an antitussive and antiallergy drug (5). The majority of research on $A$. radix focuses on its anti-allergy or anti-inflammatory effects. The aqueous extract of $A$. radix was shown to inhibit formalin-induced hyperalgesia via $\mathrm{N}$-methyl-D-aspartate (NMDA) receptors (5) and to have an anti-allergy potential through inhibition of IgE production in in vitro and in vivo models (6). Hashimoto et al reported that several single compounds derived from the methanol extract of $A$. radix presented anti-allergy effectiveness in in vitro passive cutaneous anaphylaxis (PCA) tests and inhibited the activity of 5-lipoxygenase in rat basophilic leukemia (RBL-1) cells (7). As a neuropharmaceutical agent, the methanol extract of $A$. radix exerted significant inhibitory effects on $\alpha$-amino-3-hydroxy-5-methyl-4-isoxazolepropionic acid (AMPA)-induced excitotoxicity in $\mathrm{PC} 12$ rat neuroblastoma cells (8). In addition, the methanol extract and its subfractions 
enhance memory in rats through the activation of the insulin receptor and the extracellular signal regulated kinase (ERK1/2) and through the inhibition of cholinesterase activities in the hippocampus (9). However, only limited information on the anticancer effects of $A$. radix is currently available. Takasaki et al reported that two hydrophobic lignans isolated from $A$. radix, asarinin and xanthoxylol, demonstrated antitumor-promoting activities on a two-stage carcinogenesis test using mouse skin and pulmonary tumors (10). However, they did not suggest a mechanism for the antitumor activity of the two lignans. The aim of our present study was to evaluate the ethanol extract of Asiasari radix (EEAR) on the proliferation of human HCT-116 CRC cell lines and to investigate the underlying mechanism of its anticancer effect.

\section{Materials and methods}

Preparation of EEAR. A. radix was purchased from Kwangmyungdang Medicinal Herbs (Ulsan, Korea). The identification of the Asiasarum heterotropoides var. mandshuricum F. Maekawa was confirmed by Dr Go Ya Choi, Herbal Medicine Research Division, Korea Institute of Oriental Medicine. A voucher specimen (KIOM-CRC-2) was deposited at the Cancer Research Center (KM-Based Herbal Drug Research Group, Herbal Medicine Research Division). Dried A. radix (200 g) was finely ground and immersed in $70 \%(\mathrm{v} / \mathrm{v})$ ethanol $(100 \mathrm{~g} / \mathrm{l})$. The solvent extraction was carried out by two consecutive ultrasonications for $1 \mathrm{~h}$. The extracts were filtered through Whatman No. 2 filter paper and the excess solvent was evaporated under reduced pressure using a rotary evaporator (EYELA, Japan) at $40^{\circ} \mathrm{C}$. The powdered extract (EEAR, $15.82 \mathrm{~g}$ ) was homogenized using a mortar and stored at $4^{\circ} \mathrm{C}$ for further studies. The yield of the extract was approximately $17.91 \%(w / w)$. A stock solution of EEAR was prepared at a concentration of $20 \mathrm{mg} / \mathrm{ml}$ in dimethylsulphoxide (DMSO) and stored at $-70^{\circ} \mathrm{C}$ until use.

Cell line and culture condition. Among several human CRC cell lines, HCT-116 is a favorable in vitro CRC model for investigating the cell signaling pathways targeted by anticancer chemotherapy (1). HCT-116 cells were obtained from the American Type Culture Collection (ATCC, Manassas, VA, USA) and grown in McCoy's 5A medium (Invitrogen Life Technologies, Carlsbad, CA, USA) supplemented with $10 \%$ fetal bovine serum (Invitrogen), $100 \mathrm{U} / \mathrm{ml}$ penicillin and $100 \mu \mathrm{g} / \mathrm{ml}$ streptomycin (Invitrogen) in a humidified atmosphere of $5 \% \mathrm{CO}_{2}$ at $37^{\circ} \mathrm{C}$.

Cell proliferation assay. Viable cells were quantified using the 3-(4,5-dimethylthiazol-2-yl)-5-(3-carboxymethoxyphenyl)2-(4-sulfophenyl)-2H-tetrazolium (MTS) assay (Promega, Madison, WI, USA). In brief, cells were seeded at $5 \times 10^{3}$ cells/well in a 96-well culture plate containing $100 \mu \mathrm{l}$ complete medium 1 day before drug treatment. Cells were treated with the indicated concentrations of EEAR for $48 \mathrm{~h}$. The DMSO was used as a negative control. The cultured media were removed and the cells were washed with phosphate-buffered saline (PBS) before adding the MTS working solution to minimize the interference of the drugs within the MTS reaction. One hundred microliters of $20 \%$ (v/v) MTS diluted in fresh culture medium was added and the cells were incubated for a further $30 \mathrm{~min}$ at $37^{\circ} \mathrm{C}$. Color development was monitored using a microplate reader at $590 \mathrm{~nm}$ (Molecular Devices, Sunnyvale, CA, USA).

Quantification of apoptosis. The degree of cellular apoptosis was measured using a commercially available enzyme-linked immunosorbent assay (ELISA) kit (Cell death detection ELISA $^{\text {PLUS }}$, Roche, Mannheim, Germany) according to the manufacturer's instructions. Apoptosis can be quantified since the amount of mono- and oligonucleosomes increase in the cytoplasm before plasma membrane breakdown due to the activation of endogenous endonucleases in apoptotic cells. The fragmented nucleosomes released into the cytoplasm were captured and quantified by a sandwich ELISA. In brief, exponentially growing cells were trypsinized and resuspended in the culture medium. Five thousand cells in $100 \mu \mathrm{l}$ culture medium were plated in each well of a 96-well culture plate and were left to attach to the plate for $24 \mathrm{~h}$ before drug treatment. Cells were treated with various concentrations of EEAR for $24 \mathrm{~h}$ and then cell lysates were prepared using $200 \mu \mathrm{l}$ of the lysis buffer included in the kit. Twenty microliters of each sample was subjected to the ELISA assay. The specific enrichment factors of the mono- and oligonucleosomes in the cytoplasm (the degree of apoptosis) were calculated using the following equation: enrichment factor $=\mathrm{mU}$ of the sample $(\mathrm{dying} / \mathrm{dead}$ cells) / $\mathrm{mU}$ of the corresponding negative control (cells treated with vehicle), where $\mathrm{mU}=$ absorbance $\left(10^{-3}\right)$.

Western blot analysis. Changes in intracellular protein levels by EEAR treatment were determined by western blot analysis. Cells were seeded at $1 \times 10^{6}$ cells/dish in $60-\mathrm{mm}$ culture dishes 1 day before drug treatment. Cells were treated with various concentrations of EEAR for $24 \mathrm{~h}$. The total protein was extracted with ice-cold RIPA cell lysis buffer (Thermo Scientific, Rockford, IL, USA) and the protein concentration was quantified by the bicinchoninic acid (BCA) colorimetric method (Thermo Scientific). Equal amounts of proteins were separated on sodium dodecyl sulfate-polyacrylamide gel electrophoresis (SDS-PAGE) gels and transferred to nitrocellulose membranes. The protein-blotted membrane was blocked with a $5 \%$ (w/v) skimmed milk solution in $0.1 \%$ (v/v) Tween-20 PBS for $1 \mathrm{~h}$ at room temperature (RT) and then probed with primary antibodies at $4{ }^{\circ} \mathrm{C}$ overnight. The primary antibodies were captured with suitable secondary antibodies conjugated with horseradish peroxidase for $1 \mathrm{~h}$ at RT. The immunoreactive bands were visualized with an enhanced chemiluminescence (ECL) kit (GE Healthcare, Piscataway, NJ, USA) or the SuperSignal West Femto Kit (Thermo Scientific). The antibodies used in these studies were as follows; caspase-3, caspase-8, caspase-9, poly-ADP ribose polymerase (PARP), Bcl-2, Bax, p53, p21 Waf/ Cipl, cyclin $\mathrm{B}, \mathrm{Cdc} 2$ and $\beta$-actin. All primary antibodies were obtained from Cell Signaling Technology, Inc. (Danvers, MA, USA) with the exception of PARP, which was obtained from Enzo Life Sciences (Farmingdale, NY, USA).

Cell cycle analysis. To compare the effect of EEAR on the HCT-116 cell cycle, fluorescence-activated cell sorting (FACS) analysis was performed. Cells were seeded at $1 \times 10^{6}$ cells/dish in $60-\mathrm{mm}$ culture dishes and incubated for $24 \mathrm{~h}$ for attachment. 
Then, cells were treated with the indicated concentrations of EEAR for various time intervals. Detached and attached cells were harvested and washed with ice-cold PBS. Cells were fixed in ice-cold $70 \%$ (v/v) ethanol and stored at $4^{\circ} \mathrm{C}$. For DNA staining, the ethanol-fixed cells were washed twice with PBS and stained with $50 \mu \mathrm{g} / \mathrm{ml}$ propidium iodide in PBS containing RNase A $(500 \mu \mathrm{g} / \mathrm{ml})$ for $40 \mathrm{~min}$ at $37^{\circ} \mathrm{C}$. Cell cycle phase distribution was determined with a FACSCalibur flow cytometer (BD Biosciences, San Jose, CA, USA) by analyzing at least 10,000 cells per sample.

Real time-polymerase chain reaction (RT-PCR). The intracellular p53 mRNA level was determined by TaqMan RT-PCR. Cells were treated with the indicated concentrations of drugs for various time intervals, then the total RNAs were prepared using the easy-spin ${ }^{\mathrm{TM}}$ Total RNA Extraction Kit (Intron Biotechnology, Seoul, Korea). Single-stranded cDNA was synthesized from $5 \mu \mathrm{g}$ of total RNA using the SuperScript ${ }^{\mathrm{TM}}$ III First-Strand Synthesis System (Invitrogen). Pre-validated probe and primer sets for p53 (RefSeq: NM_000546.4, ABI ID Hs01034249_m1, FAM-labeled) and $\beta$-actin endogenous control (RefSeq: NM_001101.3, ABI ID Hs99999903_m1, VIC-labeled) were purchased from Applied Biosystems (Foster City, CA, USA). The PCR reactions were run in an Applied Biosystems Sequence Detection System 7500 and the relative expression of p53 was calculated using the $\Delta \Delta \mathrm{Ct}$ method.

Gene silencing of p53. HCT-116 cells were transiently transfected for $24 \mathrm{~h}$ with $400 \mathrm{nM}$ of p53 specific siRNA or green fluorescent protein (GFP) control siRNA using Lipofectamine 2000 (Invitrogen) according to the manufacturer's instructions. The siRNA oligomers were synthesized by Genolution Pharmaceuticals, Inc. (Seoul, Korea). The sequences of the tested siRNAs were as follows: 5'-CAG TCTACCTCCCGCCATA-3' for p53 and 5'-GGCTACGTC CAGGAGCGCACC-3' for the GFP control. The effect of p53 siRNA gene silencing was determined by western blot analysis.

Statistical analysis. The continuous variables were expressed as mean \pm standard deviation (SD). One-way ANOVA was carried out to compare the differences between the groups. $\mathrm{P}<0.05$ was considered to indicate a statistically significant difference.

\section{Results}

EEAR-induced caspase-dependent apoptosis in HCT-116 cells. In the present study, the anti-proliferative potential of EEAR was investigated on HCT-116 cells with an MTS assay. The HCT-116 cells were exposed to increasing concentrations of EEAR $(0-50 \mu \mathrm{g} / \mathrm{ml})$ for $48 \mathrm{~h}$ and the cell viability was quantified using an MTS assay kit. The growth of HCT-116 cells was inhibited by EEAR in a dose-dependent manner and almost $80 \%$ growth inhibition was observed at $\geq 25 \mu \mathrm{g} / \mathrm{ml}$ EEAR (Fig. 1A). The half-maximal inhibitory concentration (IC50) of EEAR after $48 \mathrm{~h}$ of drug treatment was $15.8 \pm 0.68 \mu \mathrm{g} / \mathrm{ml}$ in HCT-116 cells. According to the US National Cancer Institute (NCI) guideline, a crude extract and a purified single compound are considered to have cytotoxic potential if their
A
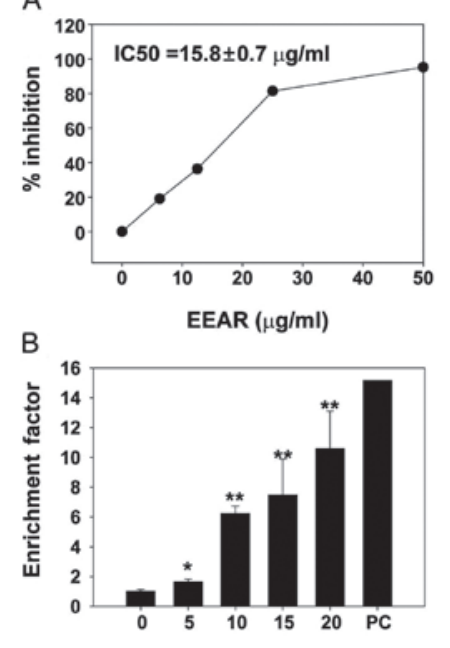

$\operatorname{EEAR}(\mu \mathrm{g} / \mathrm{ml})$
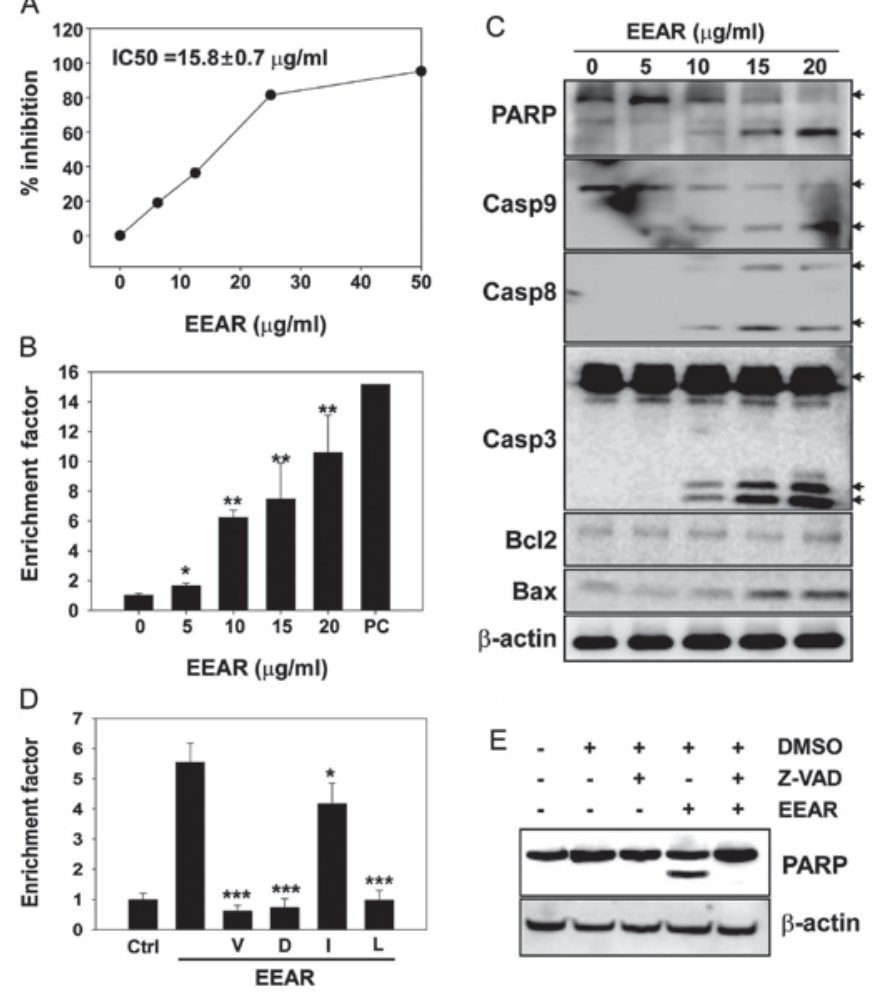

E

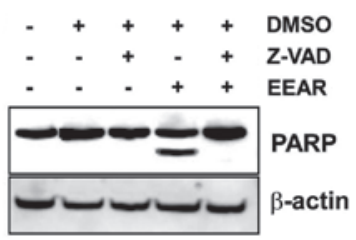

Figure 1. Induction of apoptosis by ethanol extract of A.radix (EEAR) treatment. (A) HCT-116 cells were incubated with increasing concentrations of EEAR for $48 \mathrm{~h}$ and the viability of the cells was measured using an MTS assay. EEAR repressed cell proliferation in a dose-dependent manner. The data are presented as the mean \pm standard deviation (SD) of triplicate experiments. (B) EEAR-induced apoptosis was quantified by enzyme-linked immunosorbent assay (ELISA) as described in Materials and methods. PC, positive control; DNA-histone complex. The data are presented as the mean \pm SD of triplicate experiments $\left({ }^{*} \mathrm{P}<0.05\right.$ and ${ }^{* * *} \mathrm{P}<0.01$ vs. vehicle treatment group). (C) Protein levels of PARP, caspase-3, caspase-8, caspase-9, $\mathrm{Bcl} 2$ and Bax following EEAR treatment for $24 \mathrm{~h}$. $\beta$-actin was used as the protein loading control. (D) Recovery of cells from EEAR-induced apoptosis by caspase inhibitors. HCT-116 cells were seeded at a density of $5 \times 10^{3}$ cells/ well. The cells were treated with caspase inhibitors $(50 \mu \mathrm{M})$ for $2 \mathrm{~h}$ before exposure to $10 \mu \mathrm{g} / \mathrm{ml}$ EEAR. V, z-VAD pan-caspase inhibitor; D, z-DEVD caspase-3 inhibitor; I, z-IETD caspase-8 inhibitor; L, z-LEHD caspase-9 inhibitor. The data are presented as the mean \pm SD of triplicate experiments. $\left({ }^{*} \mathrm{P}<0.05\right.$ and ${ }^{* * *} \mathrm{P}<0.001$ vs. no inhibitor treatment group in the presence of EEAR exposure). (E) Inhibition of EEAR-induced apoptosis by a pancaspase inhibitor. Equal amounts of cell lysate $(30 \mu \mathrm{g})$ were separated and transferred onto nitrocellulose membrane. The membrane was incubated with PARP antibody.

cytotoxic activities (IC50) are $\leq 20$ and $\leq 4 \mu \mathrm{g} / \mathrm{ml}$, respectively, at $48-72 \mathrm{~h}$ treatment (11). Based on this guideline, EEAR is considered cytotoxic in HCT-116 cells in vitro, which further justified our investigation.

A number of tumor therapeutics with cytotoxic activity induce apoptosis in cancer cells. To determine whether EEAR induces apoptosis in HCT-116 cells, apoptosis was quantified using a commercially available apoptosis detection kit. Cells were treated with increasing concentrations of EEAR $(0-20 \mu \mathrm{g} / \mathrm{ml})$ for $24 \mathrm{~h}$ and apoptosis was quantified using the ELISA method in which fragmented nucleosomes released from the cells undergoing apoptosis were detected as described in Materials and methods. Even at the lowest concentration of EEAR $(5 \mu \mathrm{g} / \mathrm{ml})$, nucleosomes fragmented by apoptosis were 

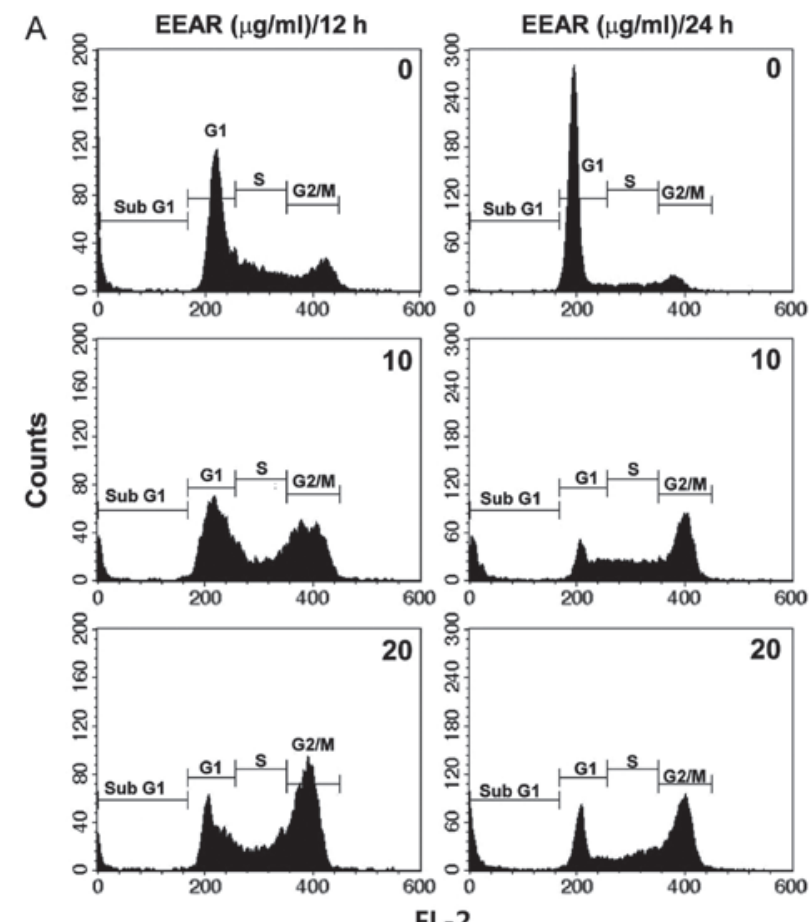

B $\operatorname{EEAR}(\mu \mathrm{g} / \mathrm{ml}) / 12 \mathrm{~h}$

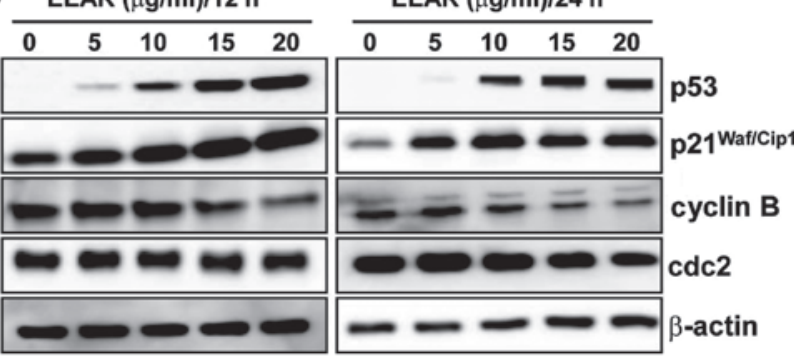

Figure 2. Effects of EEAR on cell cycle progression. (A) Analysis of cell cycle distribution by FACS. HCT-116 cells were treated with 10 or $20 \mu \mathrm{g} / \mathrm{ml}$ for the periods indicated. Cells were harvested and fixed with $70 \%$ ethanol and stained with propidium iodide. The cellular DNA content was determined by flow cytometry. (B) Effect of EEAR on the expression of the regulatory proteins related with $\mathrm{G} 2 / \mathrm{M}$ phase. Equal amounts of protein $(30 \mu \mathrm{g})$ were separated and immunoblotted by the primary antibodies as indicated. $\beta$-actin was used as the protein loading control. EEAR, ethanol extract of A. radix; FACS, fluorescence-activated cell sorting.

detected and their levels increased in a dose-dependent manner (Fig. 1B). Apoptosis caused by treatment with $20 \mu \mathrm{g} / \mathrm{ml}$ EEAR increased 11-fold compared to the control treatment.

To confirm that EEAR was able to induce apoptosis in HCT-116 cells, the expression of apoptosis-related proteins was examined by western blot analysis. HCT-116 cells were treated with increasing concentrations of EEAR $(0-20 \mu \mathrm{g} / \mathrm{ml})$ for $24 \mathrm{~h}$ and each protein was detected with specific antibodies. The cleavage of the nuclear protein PARP, a sensitive substrate of active caspase-3, was observed at $\geq 10 \mu \mathrm{g} / \mathrm{ml}$ EEAR with parallel activation of caspases (Fig. 1C). EEAR treatment elevated the expression of the pro-apoptotic cell death protein, Bax, in a dose-dependent manner. However, the expression of $\mathrm{Bcl} 2$, an anti-apoptotic cell death protein, was not affected by EEAR treatment (Fig. 1C).

Since we observed the EEAR-induced activation of caspases, which play key roles during apoptosis, we determined

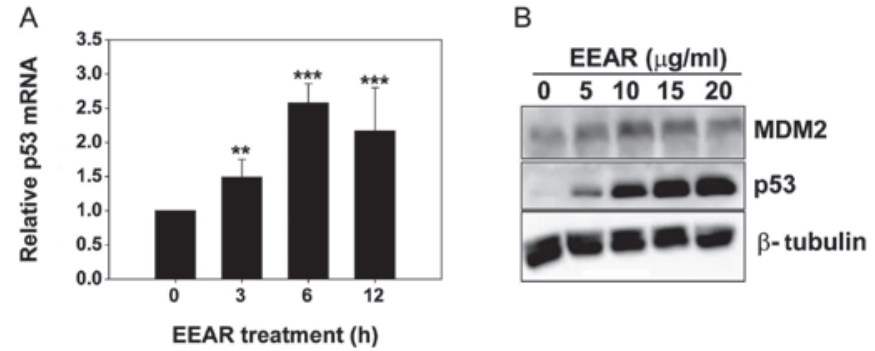

C

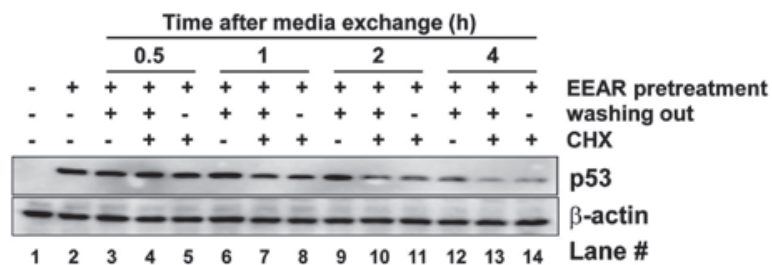

D
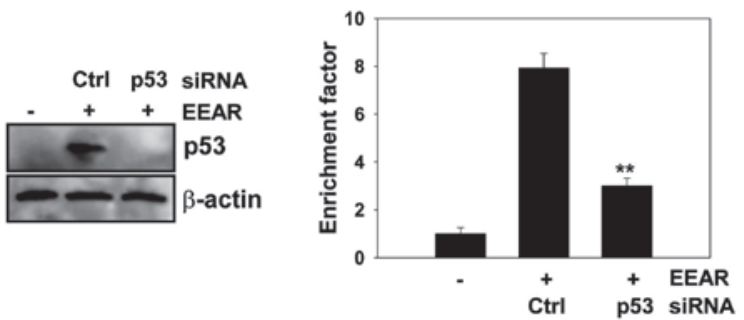

Figure 3. p53-dependent EEAR-induced apoptosis. (A) HCT-116 cells were treated with $10 \mu \mathrm{g} / \mathrm{ml}$ EEAR and total RNA was isolated at the indicated time points. cDNA was synthesized using an equal amount of total RNA and subjected to RT-PCR analysis. Data are presented as the mean \pm SD of triplicate experiments. ${ }^{* *} \mathrm{P}<0.01$ and ${ }^{* * * *} \mathrm{P}<0.001 \mathrm{vs}$. vehicle treatment group. (B) HCT-116 cells were exposed to the indicated concentrations of EEAR for $12 \mathrm{~h}$ and then MDM2 and $\mathrm{p} 53$ proteins were detected by western blot analysis. (C) HCT-116 cells were pretreated with $10 \mu \mathrm{g} / \mathrm{ml}$ EEAR for $12 \mathrm{~h}$ then cycloheximide (CHX) was added to fresh culture medium in the absence or the presence of EEAR. Total protein was prepared with RIPA buffer at the indicated time points and subjected to western blot analysis. (D) Cells were transiently transfected with p53 or GFP control siRNA for $24 \mathrm{~h}$ then treated with $10 \mu \mathrm{g} / \mathrm{ml}$ EEAR for another $24 \mathrm{~h}$. The expression of $\mathrm{p} 53$ was examined by western blot analysis (left) and apoptosis was quantified using ELISA as described in Materials and methods (right). Data are presented as the mean \pm $\mathrm{SD}$ of triplicate experiments. ${ }^{* *} \mathrm{P}<0.01$ vs. control siRNA treatment group in the presence of EEAR exposure. EEAR, ethanol extract of A. radix; RT-PCR, real-time polymerase chain reaction; SD, standard deviation; GFP, green fluorescent protein; ELISA, enzyme-linked immunosorbent assay.

whether caspase inhibitors could alleviate EEAR-induced apoptosis in HCT-116 cells. Pre-treatment with inhibitors of pan-caspases (z-VAD), caspase-3 (z-DEVD) and caspase-9 (z-LEHD) efficiently rescued the cells from EEAR-induced apoptosis (Fig. 1D). Although EEAR was observed to activate caspase- 8 , which was determined by the cleavage of the caspase-8 pro-enzyme (Fig. 1C), the protective effect of the caspase-8 specific inhibitor (z-IETD) was marginal but statistically significant. The inhibition of caspases by the pan-caspase inhibitor (z-VAD) was confirmed by complete inhibition of PARP cleavage induced by EEAR treatment (Fig. 1E). These results revealed that EEAR induces apoptosis in HCT-116 cells mainly through the intrinsic apoptotic cell death pathway.

EEAR inhibits cell cycle progression in HCT-116 cells. A variety of cytotoxic anticancer drugs are known to affect cell proliferation by disturbing cell cycle progression. To determine 
the effect of EEAR on cell cycle progression, HCT-116 cells were treated with EEAR for 12 or $24 \mathrm{~h}$ and the intracellular DNA content was analyzed using a flow cytometer. As shown in Fig. 2A, EEAR induced cell cycle arrest in the G2/M phase as early as $12 \mathrm{~h}$. After $24 \mathrm{~h}$, cells demonstrating subG1 aneuploidy, a hallmark of apoptotic cell death, accumulated in the presence of EEAR exposure. Since the progression through the cell cycle at each checkpoint is controlled by specific regulatory proteins, the changes in the expression of the regulatory proteins of the G2/M checkpoint were determined by western blot analysis. Dose-dependent dramatic increases in the p53 and $\mathrm{p} 21^{\text {Waf/Cip } 1}$ tumor suppressors and decreases in the cyclin B and cdc2 were observed in HCT-116 cells as early as $12 \mathrm{~h}$. Therefore, EEAR induces G2/M cell cycle arrest in HCT-116 cells by modulating the expression of the regulatory proteins involved in the G2/M cell cycle checkpoints.

EEAR regulates p53 expression at the transcription level. Expression of the tumor suppressor protein p53 is known to be regulated at the transcriptional and post-translational levels. We carried out quantitative RT-PCR to investigate the effect of EEAR on the level of intracellular p53 mRNA. Total RNA was isolated from HCT-116 cells at regular time intervals in the presence and absence of $10 \mu \mathrm{g} / \mathrm{ml}$ EEAR treatment. The level of p53 mRNA began to rise as early as $3 \mathrm{~h}$ after EEAR treatment and reached a plateau at $6 \mathrm{~h}$ (Fig. 3A). MDM2 is involved in the post-translational regulation of p53 stability. MDM2 binds to p53 and then recruits it from the nucleus to the cytosol, where MDM2 facilitates the ubiquitin-mediated protein degradation of p53. In HCT-116 cells, the MDM2 expression slightly increased with treatment up to $10 \mu \mathrm{g} / \mathrm{ml}$ EEAR, then it began to decrease over $10 \mu \mathrm{g} / \mathrm{ml}$ EEAR. This result did not coincide with the dose-dependent elevation of p53 expression by EEAR (Fig. 2B). Next, we determined whether elevated expression of p53 by EEAR is due to inhibition of proteasome-mediated p53 degradation by administration of a protein synthesis inhibitor, cycloheximide, in the HCT-116 cell culture media. HCT-116 cells were exposed to $10 \mu \mathrm{g} / \mathrm{ml}$ EEAR and then the culture media were exchanged with fresh media with (no washing out) or without (washing out) EEAR, in combination with cycloheximide. At regular time intervals, total proteins were prepared and subjected to western blot analysis of p53. Elevated expression of p53 by EEAR pretreatment was maintained without media exchange (Fig. 3C, lane 2). In the absence of both EEAR (washing out) and cycloheximide, p53 was maintained up to $2 \mathrm{~h}$ (lane 3,6 and 9) and began to decrease at $4 \mathrm{~h}$ (lane 12). Irrespective of the presence of EEAR, cycloheximide significantly reduced the p53 expression as early as $1 \mathrm{~h}$ post-treatment (lane 7 and 8) and almost abolished the p53 expression at $4 \mathrm{~h}$ (lane 13 and 14). These results suggest that EEAR does not inhibit proteasome-mediated p53 degradation. Taken together, the upregulation of $\mathrm{p} 53$ by EEAR was due to the increased level of intracellular mRNA.

EEAR-induced apoptosis in HCT-116 cells depends on p53. Since we observed G2/M cell cycle arrest and intracellular accumulation of p53 upon EEAR treatment, we sought to determine whether p53 is required for EEAR-induced apoptosis by knocking down p53 with siRNA. HCT-116 cells were transfected with p53-specific siRNA or a negative control,
GFP siRNA, for $24 \mathrm{~h}$, followed by EEAR treatment. Transient expression of p53 siRNA efficiently inhibited the accumulation of p53 induced by EEAR (Fig. 3D, left) and knockdown of p53 conferred resistance to EEAR cytotoxicity in the HCT-116 cells (Fig. 3D, right). These results suggest that p53 contributes to EEAR-induced apoptosis.

\section{Discussion}

The majority of the medicinal herbs called $A$. radixes originate from $A$. heterotropoides or A. sieboldii. They have been widely used in traditional Korean medicine as a component of herb prescriptions due to their diverse pharmaceutical effects, such as pain killing, anti-allergy and anti-inflammatory $(4,5)$. However, until recently, few studies reported the anticancer effect of $A$. radix (10). To our knowledge, only one mechanism of the anticancer effect of $A$. radixes has been suggested by a Japanese research group. Takara et al revealed that the whole extract of $A$. radix increased the substrate transport function of the multidrug resistance (MDR)/P-glycoprotein, a major mechanism of MDR and sensitized HeLa cervical cancer cells to paclitaxel, a well-known MDR/P-glycoprotein substrate, but not to 5-fluorouracil, which is not an MDR/P-glycoprotein substrate (12). In our study, we evaluated the in vitro cytotoxic potential of the ethanol extract of $A$. radix in HCT-116 human cancer cells and suggested the potential anticancer mechanism of $A$. radix.

We demonstrated that EEAR exerted notable cytotoxicity in a dose-dependent manner and induced apoptosis in HCT-116 cells (Fig. 1A and B). Treatment with EEAR increased the expression of Bax and induced caspase activation (Fig. 1C). The expression of the anti-apoptotic protein Bcl2 was minimally changed by EEAR; however, the overall ratio of $\mathrm{Bax}$ (pro-apoptosis)/Bcl2 (anti-apoptosis) increased. The increased $\mathrm{Bax} / \mathrm{Bcl} 2$ ratio is known to be a rheostat of cell susceptibility to apoptosis (13). Although EEAR activated the caspases involved in the intrinsic (caspase-9) and extrinsic (caspase-8) apoptotic pathways (Fig. 1C), more efficient cell recovery from EEAR cytotoxicity by pretreatment with the caspase-3 (z-DEVD) and caspase-9 inhibitors (z-LEHD) than the caspase-8 inhibitor (z-IETD) was observed, suggesting that EEAR may induce apoptosis in HCT-116 cells mainly through the intrinsic apoptotic pathway (Fig. 1D). Intrinsic apoptosis is characterized by an increased mitochondrial membrane permeability, release of cyt $\mathrm{C}$ and mitochondrial dysfunction. Intracellular reactive oxygen species (ROS) are produced upon mitochondrial dysfunction and EEAR treatment increased the intracellular level of ROS in HCT-116 cells (data not shown). EEAR-induced apoptosis was preceded by a tight cell cycle arrest in the G2/M phase (Fig. 2A), which was followed by the downregulation of cdc2 and cyclin $\mathrm{B}$ as well as the upregulation of p53 and p21 $1^{\text {Waf/Cipl }}$ (Fig. 2B). These results suggest that EEAR prevents the growth of HCT-116 cells by preventing cell cycle progress at the $\mathrm{G} 2 / \mathrm{M}$ checkpoint, which subsequently leads to apoptosis.

We demonstrated that EEAR elevates the expression of p53. As a transcriptional activator, the p53 tumor suppressor has a broad range of anticancer functions, such as the arrest of cell growth, induction of apoptosis and senescence and inhibition of tumorigenic angiogenesis through transcriptional 
regulation of its target genes (14-17). Functionally inactive mutations in the p53 gene or a lack of p53 expression have been observed in a number of cancers (18-20) and clinical studies have revealed that over $50 \%$ of human tumors carry the p53 mutation $(14,21)$. In HCT-116 cells, which are known to have wild-type p53, endogenous p53 was expressed at an undetectable level under normal culture conditions, but its expression dramatically increased upon EEAR exposure (Fig. 2B). The intracellular level of p53 is controlled by post-translational modification (22) or transcriptional regulation (23). The stability of the $\mathrm{p} 53$ protein was mainly regulated by the oncoprotein MDM2, which possesses ubiquitin ligase E3 activity. MDM2 binds to $\mathrm{p} 53$, transports it from the nucleus to the cytosol and triggers the degradation of $\mathrm{p} 53$ via the ubiquitinproteasome degradation system. From our study, we suggest that EEAR can regulate p53 expression at the transcriptional level based on two observations. First, EEAR increased the p53 mRNA level determined by RT-PCR (Fig. 3A). Second, the intracellular protein level of p53 decreased, even in the presence of EEAR treatment when cells were co-treated with the protein synthesis inhibitor, cycloheximide (Fig. 3C). However, we cannot exclude the possibility of an increase in mRNA stability leading to the elevated p53 levels observed upon EEAR treatment.

Next, we investigated whether p53 is a key modulator during EEAR-induced apoptosis. The evidence showing that efficient knockdown of p53 conferred resistance to EEAR cytotoxicity in the HCT-116 cells (Fig. 3D) demonstrates that apoptosis induced by EEAR requires the expression of p53 in HCT-116 cells. The apoptosis mediated by p53 can be either dependent on, or independent of its transcriptional activity. In the transcription-dependent pathway, transcriptionally active p53 upregulates the expression of pro-apoptotic proteins, such as Bax and p53 upregulated modulator of apoptosis (PUMA), thereby inhibiting the anti-apoptotic survival protein Bcl2. In the transcription-independent pathway, p53 cooperates with other apoptotic factors, such as E2F-1 and induces apoptosis irrespective of its transcriptional activity (24). In the present study, we could not determine which pathway the HCT-116 cells follow after EEAR treatment.

In this study, we demonstrated that the ethanol extract of $A$. radix induces $\mathrm{G} 2 / \mathrm{M}$ cell cycle arrest and apoptosis in HCT-116 human colon cancer cells in vitro through upregulation of the p53 tumor suppressor. This study increases our understanding of the cytotoxic mechanisms of EEAR and suggests that EEAR contains natural herb materials that could be used in the development of anticancer drugs. The active compounds responsible for the cytotoxic effect of the ethanol extract of A. radix will be identified in our future studies.

\section{Acknowledgements}

The authors sincerely thank Dr Go Ya Choi, Dr Sungwook Chae and Hye Won Lee, Herbal Medicine Research Division, for identification of the herbal plants and preparation of herbal extract. This research was supported by a grant from the Korea Institute of Oriental Medicine (KIOM, K12061).

\section{References}

1. Wang CZ, Luo X, Zhang B, et al: Notoginseng enhances anticancer effect of 5-fluorouracil on human colorectal cancer cells. Cancer Chemother Pharmacol 60: 69-79, 2007.

2. Chen J, Huang XF and Katsifis A: Activation of signal pathways and the resistance to anti-EGFR treatment in colorectal cancer. J Cell Biochem 111: 1082-1086, 2010.

3. Kinzler KW and Vogelstein B: Lessons from hereditary colorectal cancer. Cell 87: 159-170, 1996.

4. Jang JY, Lee JH, Shin HK, Choi YH, Lee JD and Choi BT: Partially purified Asiasari radix inhibits melanogenesis through extracellular signal-regulated kinase signaling in B16F10 cells. Int J Mol Med 25: 287-292, 2010.

5. Suzuki Y, Yuzurihara M, Hibino T, Yano S and Kase Y: Aqueous extract of Asiasari radix inhibits formalin-induced hyperalgesia via NMDA receptors. J Ethnopharmacol 123: 128-133, 2009.

6. Kim HM and Moon YS: Asiasari radix inhibits immunoglobulinE production on experimental models in vitro and in vivo. Immunopharmacol Immunotoxicol 21: 469-481, 1999.

7. Hashimoto K, Yanagisawa T, Okui Y, Ikeya Y, Maruno M and Fujita T: Studies on anti-allergic components in the roots of Asiasarum sieboldi. Planta Med 60: 124-127, 1994.

8. Han Y, Kwon EH and Kim SJ: Protection of brain cells against AMPA-induced damage by Asiasari Radix extracts. Phytother Res 17: 882-886, 2003.

9. Han Y and Kim SJ: Memory enhancing actions of Asiasari radix extracts via activation of insulin receptor and extracellular signal regulated kinase (ERK) I/II in rat hippocampus. Brain Res 974: 193-201, 2003.

10. Takasaki M, Konoshima T, Yasuda I, Hamano T and Tokuda H: Inhibitory effects of shouseiryu-to on two-stage carcinogenesis. II. Anti-tumor-promoting activities of lignans from Asiasarum heterotropoides var. mandshuricum. Biol Pharm Bull 20: 776-780, 1997.

11. Ramasamy S, Abdul Wahab N, Zainal Abidin N, Manickam S and Zakaria Z: Growth inhibition of human gynecologic and colon cancer cells by Phyllanthus watsonii through apoptosis induction. PLoS One 7: e34793, 2012.

12. Takara K, Horibe S, Obata Y, Yoshikawa E, Ohnishi N and Yokoyama T: Effects of 19 herbal extracts on the sensitivity to paclitaxel or 5-fluorouracil in HeLa cells. Biol Pharm Bull 28: 138-142, 2005.

13. Korsmeyer SJ, Shutter JR, Veis DJ, Merry DE and Oltvai ZN: Bcl-2/Bax: a rheostat that regulates an anti-oxidant pathway and cell death. Semin Cancer Biol 4: 327-332, 1993.

14. Pei D, Zhang Y and Zheng J: Regulation of p53: a collaboration between Mdm2 and Mdmx. Oncotarget 3: 228-235, 2012.

15. Futamura M, Kamino H, Miyamoto Y, et al: Possible role of semaphorin $3 \mathrm{~F}$, a candidate tumor suppressor gene at $3 \mathrm{p} 21.3$, in p53-regulated tumor angiogenesis suppression. Cancer Res 67: 1451-1460, 2007.

16. Tanikawa C, Nakagawa H, Furukawa $Y$, Nakamura $Y$ and Matsuda K: CLCA2 as a p53-inducible senescence mediator. Neoplasia 14: 141-149, 2012.

17. Rahman-Roblick R, Roblick UJ, Hellman U, et al: p53 targets identified by protein expression profiling. Proc Natl Acad Sci U S A 104: 5401-5406, 2007.

18. Hollstein M, Sidransky D, Vogelstein B and Harris CC: p53 mutations in human cancers. Science 253: 49-53, 1991.

19. Braithwaite AW, Royds JA and Jackson P: The p53 story: layers of complexity. Carcinogenesis 26: 1161-1169, 2005.

20. El-Deiry WS: The role of p53 in chemosensitivity and radiosensitivity. Oncogene 22: 7486-7495, 2003.

21. Reisman D and Loging WT: Transcriptional regulation of the p53 tumor suppressor gene. Semin Cancer Biol 8: 317-324, 1998.

22. Honda R, Tanaka H and Yasuda H: Oncoprotein MDM2 is a ubiquitin ligase E3 for tumor suppressor p53. FEBS Lett 420: 25-27, 1997.

23. Sun X, Shimizu H and Yamamoto K: Identification of a novel p53 promoter element involved in genotoxic stress-inducible p53 gene expression. Mol Cell Biol 15: 4489-4496, 1995.

24. Haupt S, Berger M, Goldberg Z and Haupt Y: Apoptosis - the p53 network. J Cell Sci 116: 4077-4085, 2003. 